\title{
Next Generation Enterprise Resource Planning: ERP II
}

\author{
Aiman J. Albarakati \\ Department of Computer Engineering, \\ College of Computer and Information Science, \\ Majmaah University, Majmaah, Saudi Arabia
}

\begin{abstract}
ERP implementations have flounced/swept from side to side the business zone from the very beginning since 1990s, serving companies to oblige losing/down outlays and maneuver further well and powerfully. ERP has permitted sectors/division heads to scrutiny their concern data more straightforwardly and cope it more in point of fact. It furthermore has modernized a host of manufacturing/industrializing and allotment progressions/processes, varying from product expansion to order processing to the logging of goods. At rest, conventional/traditional ERP has collapsed undersized in a various zones that are by means of so critical to todays or current business requirements. Foremost, its scale or range is restricted. ERP lend a hand to computerize individual departments, but with this it hasn't pulled out its back office reimbursement or merits into the front office to facilitate businesses administer people, supply chain and workload concerns. Subsequent, it hasn't set free reliable command and control of all the processes and progressions of the ongoing or current business. Aggressive demands and globalization have prepared and concluded it obvious that the business world is at a standstill in call for of more effectual, entire enterprise elucidation.
\end{abstract}

\section{Keywords}

ERP, BPM, CRM, ERP-II, Analysis and Planning

\section{INTRODUCTION}

Conventional Enterprise Resource Planning accomplishments and execution have characteristically infiltrated thereabout $15 \%$ to $20 \%$ of an association or business. The imaginative hallucination/dream that such a clarification would lay a hand on all of the processes/progressions surrounded by a business has curved/turned out to be excessively buoyant. Organizations have had to put into practice manifold elucidations to stock up a variety of data, and queries endure about how companies/corporations can strengthen and exercise their concern warehouses of information to distribute well again products/stuffs and services, whilst sustaining turnover margins. Integration/incorporation has turn out to be the gigantic problem. Information and understanding within a preponderance of organizations at present be inherent in silos that are retained by means of a decide on few, devoid/without of the capability to be public/distribute transversely or across the organization. In the present day company leaders require information to be additional readily available. They also desire real-time analysis or view/sight into their contemporary businesses so that judgment can be made when they want/need to be, Lacking the added time of tracking data and creating reports. Managers fancy to supervise key metrics in real-time to vigorously follow and keep an eye on the strength of their business. ERP was a first-class initiative, but the contemporary marketplace is demanding more and more. One prevailing conclusion/finale is that the Enterprise Resource
Planning lastly has to engross the whole venture, delivering unfailing, quantifiable processes and up-to-the-second information that chains or supports lucrative or cost effective decision making. Enterprise Resource Planning is an Enterprise broad system that smooths the progress of incorporated and real-time planning/setting up, manufacture or production and client feedback. An ERP has multilingual potential, multi-currency financial services managing aptitude, and also can be familiar with permissible and tax/tariff coverage requirements of different nations throughout the world. The genuine call for such an incorporated system has came into sight with the inception of e-business, Supply Chain Management and worldwide maneuvers which desires trade of information with further corporations and clients straightforwardly. The business we do in present world is dwindling/reducing, and practically each venture is either advertising or selling to clients in different countries, or cleanly by means of parts or materials that are fashioned somewhere else. The ubiquitous Internet has prevailed over time and remoteness/distance to an immense degree. It has now become the main part of each every hour to reflect or assume worldwide and also to comprise the similar in tactics, progression and approaches. Ideological Globalization and trade through WWW (World Wide Web) traveling on the expansion of the Internet have altered long-established and conventional business behaviors and performance. Leveraging the Internet by means of the commerce has befallen a call for quickly establishment of an implicit existence. They are obliged to utilize collaborative/mutual technology in order to act in response to client's necessities superior and more rapidly. When the maneuvers/operations are sprinkled in the course of manifold positions world widely, the requirement is that to achieve visibility athwart/across each and every site. This improved visibility can show the way to further bargaining supremacy/power for acquiring parts and more professional centralized financial records payable and receivable thus enhancing the entire performance/concert. Clarifications/solutions like CRM, SCM or ERP solutions endow with tools to cope the information which is very important for mounting business worth. Enterprise extensive computerization/automation unaccompanied can deal with renovating associations among contractors/suppliers, buyers, manufacturers and clients. ERP has plunged diminutive in the following regions that are very serious to current and upto-date business requirements [5]. Range or scope of traditional ERP is restricted; ERP lend a hand to computerize individual departments, but with this it hasn't pulled out its back office reimbursement or merits into the front office to facilitate businesses administer people, supply chain and workload concerns. Subsequent, it hasn't set free reliable command and control of all the processes and progressions of the ongoing or current business. Aggressive demands and globalization have prepared and concluded it obvious that the business world is at a standstill in call for of more effectual, 
entire enterprise elucidation.

\section{CARRYING ENTERPRISE RESOURCE PLANNING TO THE WHOLE VENTURE: ERP II}

From business point of view each and every technology need to acclimatize/adapt for shifting business atmosphere just for the cause to endure and be in the black or flourish. The Enterprise Resource Planning marketplace is no immunity/exception or omission. As trades penetrated the 21st century, they embarked on to fiddle with the initiative of comprehensive ERP accumulating to functionality that subsisted remote/outside of the ERP system into the mix. There were, and keep on to be, concerns/matters with incorporating such functionality, as businesses/trades thus far have had to put into practice any number of solutions to work out definite Information Technology issues. Enterprise Resource Planning-II is the subsequent stride/phase in comprehensive/enhanced ERP. It is that kind of solution which comprises the conventional materials/resources planning, allotment, and order-entry functionality reinforced by competence like Human Resources Management (HRM), Customer Relationship Management (CRM), Knowledge Management (KM) and Workflow Management. Such kind of a system is able to operate the entire organization quickly, accurately and consistently. It deliver/redeems information on the spot to the concern people who want or have a request for it. It administers the admittance to that information by launching protection tasks and ratings that identify which staff members can exercise definite portions of information. Furthermore it also deals with the problem of manifold office locations/positions by crafting the elucidation/solution webbased, so recruits can entrance the particular system no offense/matter wherever they are or might be... Businesses/trades are using the ultimate Internet more and more day by day. Now it is not longer only a simple gizmo or tool for email, research/exploration and commerce/trades. It is hastily flattering/becoming a tool or a kind of gun for globalizing a business, a kind of tool that permits an association to fasten together its suppliers, its staff or employees and more important their clients. It also facilitates the free flow of information, and the subsequently creation of clarifications will be built upon it. The call for e-business (electronic business), Internet willingness in this Internet age or epoch and circumstances that overcome to surge over early 2000 problems in the late 90 s and early 2000s drove Enterprise Resource Planning into the global marketplace. Normal outlay or charges of launching a money-making website for a hefty business or trade was set aside at 1 million US Dollars as documented by different Research bureaus/agencies akin to Gartner Research Group (GRG) [2]. Nearly all of the websites built up all through this period lacking backend hold/support and possibly will only acknowledge shopping cart details from clients make a hardcopy/print for them and carry out the remaining processing manually. This concludes that only front-end website survived which crafted it comes into view as if the whole thing were integrated/incorporated electronically or automatically by machine. Components/modules in the suite delivered by Oracle and System Applications \& Products (SAP) had enough functionality to catch the attention of preponderance/majority of any sort of business/trades wanting to put into operation the e-way (online payment gateway). Corporations had to exhaust plenty of cash on sustaining the interfaces/boundaries among the components/elements after putting into practice the concern system all through this premature phase of e-business propagation. With the expansion of the middleware called Enterprise Application integration (EAI), a large amount of the assimilation or incorporation problems hang about in perimeters. The dissimilarity between Enterprise Resource Planning, newgeneration application packages and e-business on track fading away from identification at the precincts/boundaries. The early ERP can be deliberated of as totally integrated/incorporated modules which endows with automated/computerized support/hold for different functions/tasks or activities. In early 1999,s, ERP by means of foremost retailers/vendors began to start slot in Internet based technologies to carry out or execute transactions or dealings all the way through an internet browser and these vendors/sellers renamed themselves as e-business purveyor/vendors. Then in 2000, the marketplace glimpsed the propagation of e-business suites/groups which might even/yet overwhelm other tasks like Supply Chain Management (SCM) and Customer Relationship Management (CRM) which were not at hand in long-established ERP. This crafted the ERP in this hefty Internet age truly prop up the ebusiness so called electronic business wave/signal and the palm top for Enterprise Resource Planning connectivity from distant sites or positions in fact revolutionized the line of attack and way how the business or trades were executed. Real time connectivity and secured centralized data repository (storage area) befallen characteristics of the Enterprise Resource Planning system. Furthermore, ERP vendors/sellers sustained a variety of versions of the system and its interfaces/boundaries expanded were by them in this manner mitigating the clients who set out/go for best of the breed. Ebusiness (Electronic Business) and ERP incorporation in reality heighten the perception/idea of digital firm that was catching/grasping the wave/signal somewhere at that specific time. Digital firm in provisions or stipulations has to owe/have a digitally permitted atmosphere or setting for the communication and dispensation/processing among Staff or employees, Clients, stakeholders and the employer [1]. ERP II has taken the place of ERP and its two smaller recognized iterations called comprehensive or expanded ERP and Enterprise Application Suite (EAS) [7]. The mainly obvious modification or shifting from Enterprise Resource Planning to Enterprise Resource Planning II or extended Enterprise Resource Planning is an adjustment in spotlight/focus from one which is entirely enterprise-centric and preoccupied/deliberated with domestic resource or supply optimization and transactional processing/dispensation or dealing out to a novel center of attention on progression/process incorporation or integration and exterior cooperation or association. Enterprise Resource Planning II application exploitation approaches or tactics recount or narrate to information which is swapped over among businesses/trades utilizing Internet. And this information switching through Internet is known as collaborative or cooperative commerce or c-commerce. Hence this concluded that ERP II has the features of c-commerce and it has also extended to embrace areas/zones such as Knowledge Management (KM), Customer Relationship Management (CRM), Supply Chain Management (SCM), inventory optimization (IO) and business intelligence (BI). ERP II features are very much in line or queue with the Gartner article which envisaged or anticipated that it would acquire conventional ERP establishment or base and would broaden it external to place the venture/enterprise in the supply chain [6]. 


\section{DIFFERENCES BETWEEN ERP AND ERP II [4]}

- $\quad$ ERP II is web enabled as compared to Conventional ERP Which is not.

- ERP is restricted to provide selected exhaustive or rigorous or wide-spread coverage in its modules. But as compared to ERP, ERP II provides the true and accurate blend of the macro and the micro and affords customers with curative actions/measures after identifying the slip-up/error or fault;

- $\quad$ ERP was embattled more headed for manufacturing or industrialization and the dilemma or difficulty is conquer in ERP II by endowing clarification for all kind of industries and sectors.

- $\quad$ ERP is not in the position or could not possibly integrate/incorporate diverse functions from diverse departments/divisions but ERP II could possibly do so as well as from different industries as compared to conventional ERP.

- $\quad$ For WEB and WAP connectivity ERP II grip CRM and SCM Functionalities.

- ERP II be obliged the function and purpose to an external/outdoor one and smooth the progress of better networks than remaining as internal/interior application.

\section{ENTERPRISE SPACIOUS AND BROAD SOLUTION}

For today's functional level competition, businesses/trades ought to espouse or accept an enterprise-wide approach/strategy to ERP that exploit/exhaust the Internet and hooks up to every feature of the value chain. They are obliged to transform or alter their individual in-house processes/progression and measures or policies to promote collaboration endeavors both within and outside the concern organization and they ought to assimilate/integrate such technologies which permit their collaboration efforts and hard works to seize jam-packed flight. Altering internal or in-house processes isn't for all time trouble-free. Businesses have to throw away aged techniques that endeavor to conserve and shield data in individual fiefdoms. They also ought to permit data to be shared inside an organization/division on a rulesand roles-based system. They also have to renovate coverage/reporting formations/structures that bound decisionmaking to decide on few. They ought to unlock lines of communication and collaboration/cooperation inside the organization/division and to remote or outside partners, customers and suppliers. Devoid of open processes, the expansion of Enterprise Resource Planning all through an enterprise will fail. Systems that leverage advanced levels of ERP-II functionality incorporate dissimilar software packages in such a way that is faultless or flawless and obvious to those utilizing them. A solitary interface loads/lots information from separate or individual systems, permitting it to be customized and saved back. Events can activate actions in individual systems, follow-on in a chain of measures/actions across the enterprise and all through the value chain. Software suppliers ought to endow with vehicles to hook up conventional Enterprise Resource Planning capabilities/aptitudes with front-office processes/progression. They have to facilitate organizations to bring together the people, processes and knowledge that matter always or all the time to a business. By connecting conventional Enterprise Resource Planning with sophisticated tools that assist run a business/trade, users can generate or make an exact, up-to-the-moment vision of the comprehensive enterprise to improve scrutiny, scenario planning, decision-making, and ongoing administration of the value cycle. This approach/method also grants organizations with the exclusive capability to observe where processes intersect/overlap, how they bang or blow each other, and the workflow that obliges them to construct an obvious picture of the business/trade, guiding towards to cost or outlay savings and operational efficiencies. Solutions/elucidations that conduit the fissure between the back and front-office worlds confers associations or business the capability to barter or switch over information with the Enterprise Resource Planning clarification. They also strap further functionality, such as granting elected persons within and outside the corporation trouble-free entrée to information serious to their work function or responsibility in the value cycle through a Web-based interface. The outcome: a substantive bloodthirsty benefit. Truthful enterprise-wide/broad clarification or way out fashion an atmosphere in which corporations can not only mock-up, but resourcefully streamline or restructure workflow and automate/computerize manual, unsecured processes/progressions into a protected centralized milieu or atmosphere. Way in to information and documents ought to be roles-based and rules-based plan, granting company managers the knack or aptitude to be in command of entrée to data on a need-to-know and need-to-access basis for projects and exterior supervised maneuvers. This roles- and rules-based strategy eradicates the "data islands" result innate in nearly all, if not all, Enterprise Resource Planning exploitations. But most prominently, advanced Enterprise Resource Planning has call for of a commanding workflow component/module. Workflow that recommends each and every member of the value chain, based on their roles/tasks and responsibilities, with a process-centric outlook of the business. Workflow that does not rely upon a crude "send"--only sculpt/model like email, but on a business-rules system which automates the stream of communication and duties. Workflows that can guarantee that allocated tasks/duties are completed or finished, or lofted if require being. Workflow that can be exercised in concurrence with sophisticated alert supervision technology to create confident that prospective/potential difficulties in the manufacturing chain do not turn into disasters.

\section{ERP REVOLUTION REVIEW}

A worldwide assessment was drifted or glided by the researchers or scholars to study or glimpse the rank of the exploitation of newest technologies like Artificial Intelligence (AI) and tools in constructing or crafting astuteness/intelligence in the contemporary age Enterprise Resource Planning [3]. Various of the novel troublesome technologies like XML extensible mark-up language, managed code and component architecture, born out of Object Oriented programming (OOP), are significant studying/revise to set up the altitude/level of utilization in mounting and employing such technologies in edifying/building Enterprise Resource Planning systems. An assessment reaction scrutiny based on responses from 92 subjects lends a hand to wrap up that 84.8 percent granted or decided that ERP entails intelligence/acumen for crafting exploitation of ERP systems in premeditated decision/verdict making or building which authenticates the subsistence of a reengineering trail/path all the way through integration of Artificial Intelligence methods 
or skills in ERP. It also can be concluded that ERP is by now in the corridor of development since 75 percent deviated or differed that ERP is fine for transaction processing only. In this web-enabled era of only internet, web-enabled application software's can endure and sustain and the similar is illustrated in the result since 80.1 percent approved that web-enabled ERP facilitates the fruition and enhancement of ERP. Nevertheless it is brought into being that Enterprise Resource Planning is in its advancement path, it is obvious that adequate scope/range subsists for the application of Artificial Intelligence procedures as 71.7 percent disavowed that extensive exploitation of Artificial Intelligence techniques/methods are accessible in present day ERP. Progression is unavoidable for Enterprise Resource Planning since 87.5 percent disavowed that ERP will hang about only as a transaction processing system (TPS). Majority (79.3 percent) conflicted that complexity in constructing intelligence/acumen in ERP is due to be short of accessibility of web tools which bestows or grants an obvious sign that technology is geared up for building/crafting intellectual ERP. Also it might be distinguished that 75 percent disagreed that aptitude/intelligence is not incorporated in ERP just because of protection reasons which entails that no security allied problems obstructs integrating intelligence/aptitude in ERP. Round about half of the respondents (48.9 percent) deviated that foremost ERP vendors/retailers doesn't desire to risk/peril by mounting clever ERP in the marketplace. The genuine cause is short of curiosity of ERP vendors/retailers in budding or mounting intelligent/clever ERP could possibly be endorsed to some other grounds other than monetary/financial menace/risk since 36.96 percent were hesitant of this reason. Majority (85.9 percent) disavowed that Enterprise Resource Planning being an assignment grave/critical real time system, intelligence should not be incorporated which means mission/task criticality of the real time ERP system doesn't plunk or set in the way of crafting/making intelligent/clever ERP. Comparatively fine proportion of respondents (59.8 percent) opposed that Artificial Intelligence techniques/methods and web tools are not mature enough for incorporation in ERP representing that Artificial Intelligence techniques/methods and web tools are ready enough for incorporation in Enterprise Resource Planning.

\section{CONCLUSIONS}

Regarding hefty and bloodthirsty contest, contemporary business/trade or commerce milieu/environment and the accessibility of the ubiquitous Internet are the only place which strains or hassle the call for Enterprise Resource Planning. Development of Enterprise Resource Planning is presented in brief preliminary with Pay roll and Bill of Materials in the early 60s to Web enabled Enterprise Resource Planning in the Y2K. Outstanding characteristics/features of Enterprise Resource Planning II that crafts it special or dissimilar from traditional ERP are presented or existed furthermore for illustrating a number of the unsettling or disturbing technologies which assist to reengineer Enterprise Resource Planning systems hasty.

\section{REFERENCES}

[1] Laudon, K C and Laudon, J P., Managing Information Systems: Managing the digital firm, 7th Edition, Prentice Hall of India, New Delhi, 2002.

[2] Shields, Murrell G., E-business and ERP, John Wiley \& Sons, USA, 2001.

[3] Suresh Subramoniam, Shehzad Ghani, K. and Krishnankutty, K V. (2006), "Current trends in enterprise information systems", Applied Computing and Informatics, Saudi Computer Society Journal, Vol.5, No. 2.

[4] www.erpwire.com/erp-articles/erpII-vs-erp.htm

[5] www.exactamerica.com

[6] www.gcis.ca/english/cdne-077-aug-16-2001.html

[7] www.vendorshowcase.com/Research/ResearchHighlight s/Erp/2004/06/research_notes/TU_ER_XSW_06_18_04_ 15.asp 